
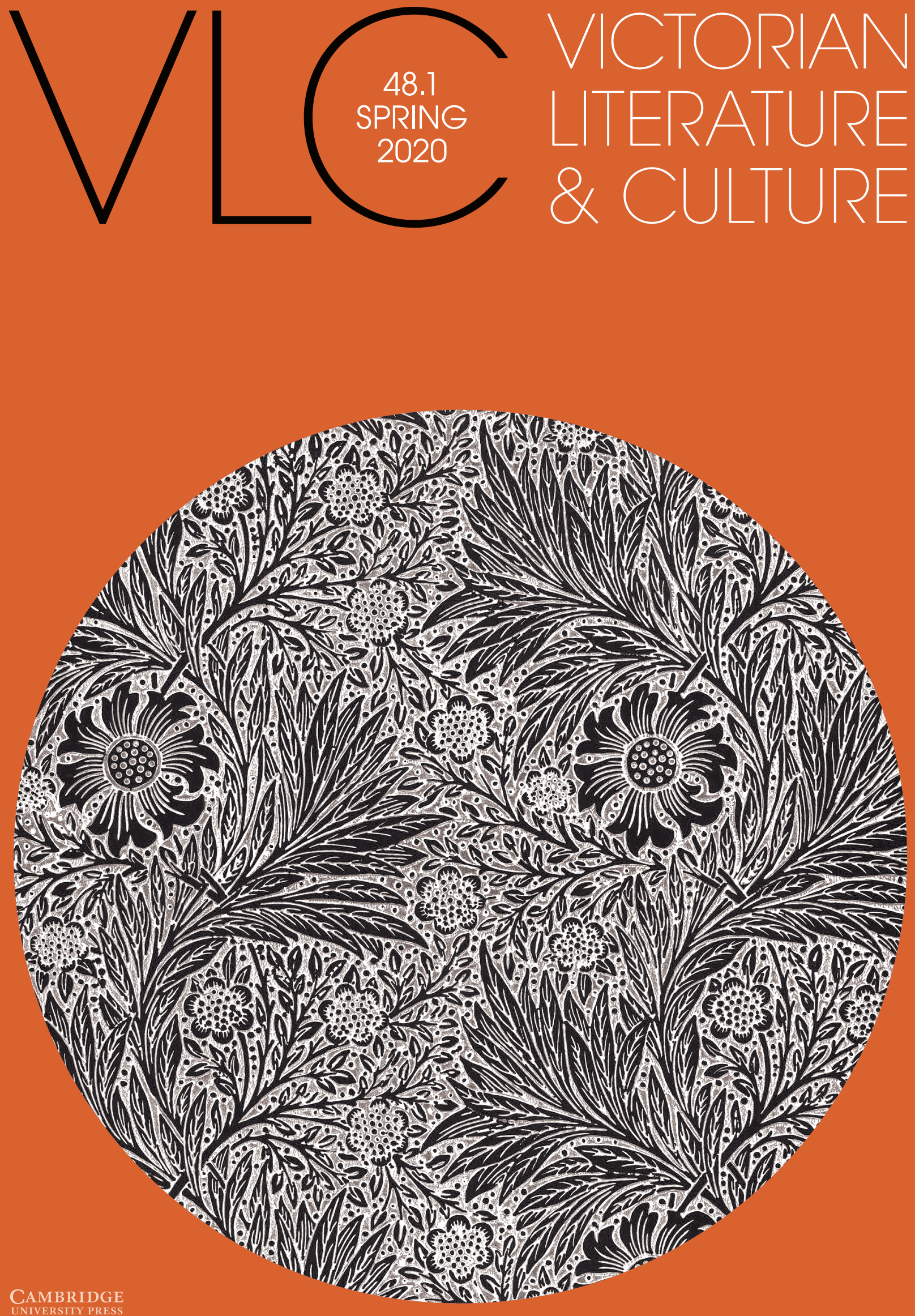


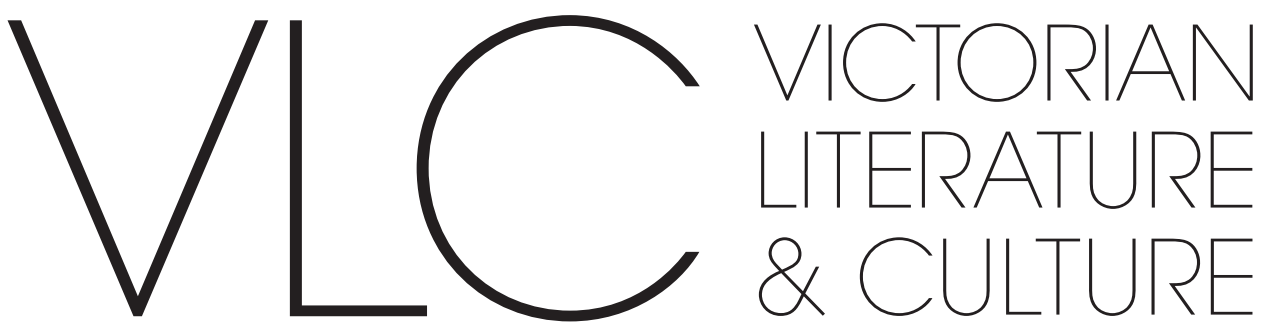

Editors

Rachel Ablow

Daniel Hack

Editors Emeriti

John Maynard

Adrienne Munich

Editorial Assistants

Callie Ingram

Evan Radeen

James Eli Adams

\section{Advisory Board}

Amanda Anderson

Isobel Armstrong

Nancy Armstrong

Sukanya Banerjee

Gillian Beer

James Buzard

Susan P. Casteras

William A. Cohen

Ian Duncan

Regenia Gagnier

Lauren M. E. Goodlad

Anne Humphreys

Audrey Jaffe

U. C. Knoepflmacher

Caroline Levine

George Levine

Tricia Lootens

Sharon Marcus

Andrew H. Miller

J. Hillis Miller

Benjamin Morgan

Upamanyu Pablo Mukherjee

Lynda Nead

Jeff Nunokawa

John Plotz

Yopie Prins

Cannon Schmitt

Hilary M. Schor

Talia Schaffer

Linda Shires

Jonah Siegel

Ruth A. Solie

Richard Stein

Margaret Stetz

Herbert Tucker

Martha Vicinus

Tim Watson

Jerome J. McGann

Carolyn Williams 
VICTORIAN LITERATURE AND CULTURE is a publication of Cambridge University Press. It is published with the generous support of the University at Buffalo, SUNY.

Victorian Literature and Culture seeks to publish innovative scholarship of broad interest to the field. We are especially interested in work that contributes or responds to the current moment of heightened methodological reflection, theoretical energy, and formal experimentation. We welcome submissions that aim to reimagine the field of Victorian studies in the twenty-first century, whether by interrogating the field's scope, boundaries, methods, and shibboleths; leveraging new or neglected conceptual resources; exploring new archives; discovering or establishing new cross-field connections; or engaging anew with the field's own history. We are open to experiments in genre and form and welcome queries about the suitability of particular submissions.

Submission Guidelines

- All manuscripts should be double-spaced and should conform to the Chicago Manual of Style, 17th edition, with abbreviated footnote citations and a bibliography. (See sections 14.19 and following.)

- Essay manuscripts should be between 7,000 and 12,000 words. (Word length for book reviews, Defamiliarizations, etc., should be worked out in advance with the editors.) All essay submissions should be accompanied by an abstract of no more than 200 words.

- For blind reading purposes, the author's name, affiliation, and contact information should appear nowhere on the submission; they should be included only in the submission email and/or Title Page.

- We welcome all submissions via our online portal at https://mc.manuscriptcentral.com/vlc. Submissions should be uploaded as Word documents.

Special Issues: The editors of $V L C$ welcome proposals for special issues or clusters. Proposals that include contributor names and paper abstracts will be given preference, but proposals in earlier states of development may be considered. Please send all queries to victorianlitandculture@gmail.com.

Publishing, Subscription, and Advertising Offices: Victorian Literature and Culture is published quarterly, in March, June, September, and December, by Cambridge University Press, One Liberty Plaza, 20th floor, New York, NY 10006. Periodicals postage rate paid at New York, NY, and at additional mailing offices. POSTMASTER: Send address changes in the USA, Canada, and Mexico to: Victorian Literature and Culture, Cambridge University Press, Journals Fulfillment Department, One Liberty Plaza, 20th floor, New York, NY 10006. Send address changes elsewhere to Victorian Literature and Culture, Cambridge University Press, Journals Fulfillment Department, UPH, Shaftesbury Road, Cambridge CB2 8BS, England. 2020 annual institutional subscription rates (print and electronic): US $\$ 426.00$ in the U.S., Canada, and Mexico, UK £ 258.00 elsewhere; (electronic only) US $\$ 314.00$ in the U.S., Canada, and Mexico, UK £ 189.00 elsewhere; (print only) US $\$ 408.00$ in the U.S., Canada, and Mexico, UK $£ 245.00$ elsewhere. Individual rates (print only): US $\$ 84.00$ in the U.S., Canada, and Mexico; UK $£ 52.00$ elsewhere. Individual rates (electronic only): US $\$ 84.00$ in the U.S., Canada, and Mexico; UK $£ 52.00$ elsewhere. For orders and subscription information, please e-mail: journals-subscriptions@cambridge.org. For ad sales, contact USAdSales@cambridge.org (US); ad-sales@cambridge.org (UK and elsewhere). The Cambridge University Press website for Victorian Literature and Culture is http://cambridge.org/vlc.

(C) Cambridge University Press 2020. All rights reserved. No part of this publication may be reproduced, in any form or by any means, electronic, photocopy, or otherwise, without permission in writing from Cambridge University Press. For further information see http://us.cambridge.org/information/rights/ or http://www.cambridge.org/uk/information/rights/

Photocopying information for users in the U.S.A.: The Item-Fee Code for this publication (1060-1503/15 \$15.00) indicates that copying for internal or personal use beyond that permitted by Sec. 107 or 108 of the U.S. Copyright Law is authorized for users duly registered with the Copyright Clearance Center (CCC), provided that the appropriate remittance of $\$ 15.00$ is paid directly to: CCC, 222 Rosewood Drive, Danvers, MA 09123. Specific written permission must be obtained for all other copying.

Printed in the United States of America.

Cover design by Julian Montague. 


\title{
CONTENTS
}

Volume 48, Issue 1

Spring 2020

\author{
Special Issue: Open Ecologies \\ edited by Devin Griffiths and Deanna K. Kreisel
}

Introduction: Open Ecologies

\section{Devin Griffiths and Deanna K. Kreisel}

\section{Disturbance}

Drill, Baby, Drill: Extraction Ecologies, Open Temporalities, and Reproductive Futurity in the Provincial Realist Novel

Elizabeth Carolyn Miller

Conrad's Carbon Imaginary: Oil, Imperialism, and the Victorian Petro-Archive

Michael Tondre

Breathing Free: Environmental Violence and the Plantation

Ecology in Hannah Crafts's The Bondwoman's Narrative

Emily Waples

Down the Slant towards the Eye: Hopkins and Ecological Perception

\section{Daniel Williams}

\section{Edge}

The Ecological Plot: A Brief History of Multispecies Storytelling, from Malthus to Middlemarch

John MacNeill Miller

George Eliot's Estuarial Form

Kyle McAuley

Henry Mayhew, Urban Ecologist

\section{Barbara Leckie}


Microbiome

Intimate Ecologies: Symbioses in the Nineteenth Century Jeanette Samyn

Pulpy Fiction

Ella Mershon

Silas Marner and the Ecology of Form

299

Devin Griffiths 